\title{
Jogos de aprendizagem inventiva
}

\author{
Gerson Klein \\ Curso de Jogos Digitais Uniritter - Laureate Universities \\ gerson_klein@uniritter.edu.br \\ Maria Cristina V Biasuz \\ CINTED-PGIE - Universidade Federal do Rio Grande do Sul \\ mcbiazus@gmail.com
}

Resumo. Esse artigo apresenta uma articulação do conceito ferramenta Caixa de Areia numa perspectiva de aprendizagem inventiva com base em Vigínia Kastrup; 0 embasamento dado por Duplesis sobre os processos de subjetivação da experiência de jogo; da classificação de tipos de atividade lúdica de Callois; das teorias de Game Design sobre jogos Caixa de Areia de Breslin e uma aproximação do tema com a práxis mediante as propostas do Game Design Racional e Design Atômico de McEntee, o artigo propõe uma discussão sobre pistas para a realização de jogos com fins de promover espaços para a problematização e a aprendizagem inventiva. Conclui-se que uma abordagem de planejamento de jogos inventivos, dentro da perspectiva da Caixa de Areia é compatível com o Game Design Racional e que a as aproximações de projeto baseadas na progressão projetada dentro das recomendações da teoria do fluxo de Csikszentmihalyi ocupam lugar privilegiado nessa discussão.

Palavras-chaves. : Aprendizagem Inventiva, Jogos, Caixa de Areia,

\section{Inventive learning games}

Abstract. This article presents an articulation of the sandbox tool concept in an inventive learning perspective based on Vigínia Kastrup, along with the basis given by Duplesis on the subjectivation processes of the gaming experience, the classification of types of playful activities by Callois, the Game Design theories on Breslin's Sandbox games, and an approach of the theme with the praxis through the proposals of McEntee's Rational Game Design and Atomic Design. The article brings a discussion concerning clues on the realization of games in order to promote room for problematization and inventive learning. It is concluded that an inventive game-planning approach, within the sandbox perspective, is compatible with the Rational Game Design and that the design approximations based on the projected progression within the recommendations of the Csikszentmihalyi flow theory are important in this discussion.

Keywords. Inventive Learning, Games, Sandbox, 


\section{Introdução}

A temática apresentada nesse artigo pode ser compreendida a partir dos seguintes questionamentos: Qual é a dimensão inventiva nos jogos ? Como a teoria do Fluxo é fundamental para o entendimento de como os jogos retroalimentam a satisfação dos jogadores?

Como a tipificação das atividades lúdicas em estruturadas e não estruturadas permitem conhecer melhor o conceito da Caixa de Areia? Como se dá o design e a elaboração de um jogo para a aprendizagem inventiva?

A aprendizagem é antes de mais nada invenção de problemas. O problema aqui, aparece como caráter próprio de uma situação que não tem um único significado. Para Kastrup (2001), a aprendizagem inventiva é experiência problemática. Da sensação se desenvolve o que chamamos de lembrança, da lembrança repetida de um mesmo objeto nasce a experiência.

É uma produção e invenção da realidade onde a experiência de fazer perguntas é diferente da experiência de compreensão. A experiência de compreensão envolve a integração de habilidades. No caso da percepção, o reconhecimento ocorre na síntese da sensação e da memória.

A compreensão é definida pelo movimento do mesmo objeto, onde todas as faculdades concordam que deve ser o mesmo: você pode ver, tocar, lembrar, imaginar e conceber que o objeto é o mesmo objeto. Mas um objeto só é reconhecido quando uma faculdade o vê como idêntico ao de outra ou, melhor, quando todas as faculdades referem seu dado confirmando uma forma do objeto, o objeto pode ser identificado (Gilles Deleuze, 2018).

Este é o meu quarto, esta é a praça perto da minha casa, este é um rosto familiar. Estes estímulos cintilam rastros da ativação da memória. Depois, há uma síntese, que é a fonte da atividade de identificação. Ao contrário dos processos que envolvem o reconhecimento, as faculdades (percepção, sensibilidade, memória e imaginação) comportam-se de maneira inconsistente em experiências problemáticas. Por exemplo, quando uma pessoa faz uma viagem para um país estrangeiro, as atividades mais comuns, tornam-se problemáticas. A expansão do escopo desse sujeito da aprendizagem que, finalmente passou por um grande processo de desindividuação e ampliação, alcançando novas dimensões que podem ser consideradas fundamentais para a construção de uma aprendizagem inventiva (Pascual et al., 2009).

Ao adentrar em um campo ao qual não estamos próximos, somos obrigados a vagar em certa medida, perdendo tempo, explorando o ambiente com o olhar focado nos signos e permeando uma nova semiótica. Portanto, apresentar um comportamento errante em torno de uma nova situação, não se trata apenas de uma questão de insciência, mas da estranheza e da tensão entre o conhecimento anterior e a experiência atual. Uma situação nova surge, então, como, oportunidade de aprendizagem, porque esta pessoa não percebeu que, a rigor, a relação que as relações que tomava como óbvias e garantidas eram, a rigor, construídas e inventadas. Esse aprendizado não termina com a resolução do problema imediato, mas prolonga seu impacto e a possibilidade de problematização (Kastrup, 2001).

Estar imerso em um novo contexto, conduz à necessidade de criação de coerência pela assimilação-eliminação que cria modos de ligação específicos, singulares em sua configuração. Modos os quais se perpetuam no tempo em um contágio de si que forma uma série de variações: contágio de si para si que produz um "si outro" (FONSECA; COSTA, 2013).

Para fins de aprendizagem inventiva, parece importante considerar a externalidade da relação de aprendizagem, pois é no nível de agência e relacionamento, inferindo-se o fórum pessoal íntimo, a principal matéria-prima é a mais importante: a invenção. Então, o processo 
de aprendizagem inventiva não ocorrerá dentro da imanência psicológica do suposto sujeito aprendiz, pois na origem do pensamento, há o contato violento com signos e forças, que estão além do nosso conceito de individualidade (Pascual et al., 2009).

\section{A dimensão inventiva nos jogos - é preciso transformar para conhecer}

Na maioria das sociedades, o brincar está situado abaixo da lista de importantes valores sociais, e é frequentemente relegado ao playground, onde atuam como uma fuga sem sentido da realidade.

No entanto, diferentes formas de jogo podem gerar, aquilo que Deleuze, (1988) chamou de transformações horizontais: o estabelecimento de uma densa continuidade entre transformações diferentes, que podem, por sua vez, produzir linhas de força que se intensificam à medida que as pessoas são afetadas pelos eventos. A vida presente na arena, torna esse, um espaço de invenção.

Nesta perspectiva, o brincar não é uma ocasião de puro desperdício, mas uma força geradora que pode fazer diferença e entrar em múltiplas áreas da vida (DU PLESSIS, 2018).

Por meio da sensibilização obtida na atividade, o jogador experimenta esse conjunto de ações como um problema ou área de desafio que exige que ele responda. A experiência no jogo aumenta a aceitação dos diferentes sinais enviados pelos vários componentes lúdicos.

Devido à mistura de ação e consciência, a sensibilização ao jogo leva à perda da autoconsciência, e é acompanhada pela experiência de união com o domínio do problema, e, portanto, leva à possibilidade de devir, no jogo, o tempo é a duração, ou seja, a percepção imediata do desdobramento complexo do tempo, o que pode levar a pensar que cada componente do conjunto tem sua própria duração (DU PLESSIS, 2018). Semelhante à perda de autoconsciência, as mudanças no tempo também podem levar a novas mudanças de escopo. Pensando em como reagir e manipular cada elemento ou antecipando os movimentos de cada componente do tabuleiro, jogadores podem potencialmente expandir seu próprio devir.

\section{A teoria do Fluxo}

Com um nível constante de dificuldade ao longo da experiência, e com o jogador tornandose cada vez mais hábil, o nível de dificuldade começa a diminuir ligeiramente em relação ao nível de habilidade obtido pelo jogador. Essa é a chave para o entendimento de como os jogos retroalimentam a satisfação dos jogadores ao oferecer padrões em uma escalada constante para que eles decifrem (KOSTER, 2005). O conceito de fluxo de Csikszentmihalyi é baseado em sua pesquisa sobre a experiência "ideal" ou "máxima" de jogadores de xadrez, dançarinos, artistas, alpinistas e cirurgiões. As pessoas que participaram dessas atividades muito diferentes descreveram suas melhores experiências em termos muito semelhantes, e Csikszentmihalyi se referiu coletivamente como "fluxo".

O processo é caracterizado pela fusão de ação e consciência, ou seja, as pessoas estão tão envolvidas no que estão fazendo que a atividade se torna espontânea, quase automática (CSIKSZENTMIHALYI, 1990).

O feedback contínuo é essencial, porque a sua interrupção pode fazer com que o foco seja disperso, o que então separa a ação da consciência e, por fim, leva à interrupção do processo. Segundo Csikszentmihalyi, esse elemento é uma das razões pelas quais todos os tipos de jogos podem produzir uma experiência tranquila, pois geralmente contêm uma gama limitada de estimulação (equipamento mínimo, espaço fechado, regras e objetivos claros). Assim, apenas o feedback contínuo no âmbito de uma estimulação imediata pode trazer a 
experiência ideal.

O processo tem um vago senso de controle. Ou seja, quando uma pessoa experimenta esse tipo de fluxo, ela se sente no domínio até certo ponto, mas paradoxalmente, ela carece de "preocupação em perder esse controle, o que é típico de muitas situações da vida normal". E esse fluxo que pode levar à perda de autoconsciência (CSIKSZENTMIHALYI, 1990).

É importante notar que essa perda de autoconsciência não é uma ausência de consciência ou mesmo uma perda de atenção, mas uma unificação do conteúdo da atividade com o eu.

Para Caillois (1990), o brincar espontâneo, chamado de Paidia, termo grego escolhido pelo autor por se relacionar com a palavra criança, é a energia primária da improvisação e da alegria. São definidos como esse vocábulo, que abrange as manifestações espontâneas do instinto do jogo: o gato aflito com o novelo de lã, o cão sacudindo-se e o bebê que ri para a chupeta, representam os primeiros exemplos identificáveis deste tipo de atividade. Ela intervém em toda animada exuberância que traduza uma agitação imediata e desordenada, uma recreação espontânea e repousante, habitualmente excessiva, cujo caráter improvisado e desregrado permanece como sua essencial, para não dizer única razão de ser (Caillois, 1990).

Normalmente, as primeiras manifestações de Paidia não têm nomes e, segundo o autor, tampouco, precisamente porque não fazem parte de nenhuma ordem única ou significado simbólico (Caillois, 1990). Aqui, mais uma vez é mencionada a relação do brincar espontâneo (Paidia) com a ambiguidade simbólica. Caillois (1990) afirma que também intervêm nessa tendência de regulamentação da Paidia o prazer que se sente com a resolução de uma dificuldade tão propositadamente criada e tão arbitrariamente definida, que o fato de a solucionar tem apenas a vantagem de satisfação íntima de o ter conseguido. Esse ímpeto é o que o autor chama de Ludus. O Ludus surge como complemento e adestramento da Paidia, que ele disciplina e enriquece. De uma forma geral, o Ludus sugere o desejo primitivo, que se alegre e divirta com obstáculos ocasionais perpetuamente renovados. Inventa mil situações e mil estruturas em que tragam a oportunidade de satisfazer-se, quer o desejo de tranquilidade quer a necessidade de que o homem parece não se libertar, de utilizar a fundo perdido o sabor de haver empenhado, a habilidade e a inteligência de que dispõe. Sob esse aspecto, o Ludus, representa no brincar, o elemento cujo alcance e profundidade culturais são mais surpreendentes. O Ludus disciplina a Paidia e dedica-se indistintivamente a dar categorias fundamentais do brincar a sua pureza e a sua excelência (Caillois, 1990). Ludus e Paidia conjuram uma relação com os objetos que cercam o corpo e refletem a ação possível do corpo sobre eles (Bergson, 1999). É na relação (percepção) que constitui o sujeito com a matéria que se dá a delimitação do mundo de cada um, tal campo é definido pelo "o que eu posso", minhas possibilidades de ação (futuro) mescladas à minha memória (passado) definem as tensões atuais do meu campo do atual (experiência presente), aquilo que existe e como existe (Fonseca et al., 2013).

\section{A Caixa de Areia}

A metáfora de "Caixa de Areia" implica algo puro e gratuito. Isso significa que uma criança na Caixa de Areia e tem imaginação infantil idealizada e inventividade ilimitada.

No universo dos jogos, a Caixa de Areia descreve um ambiente limitado que pode fornecer exploração e construção livres. Os jogos desse gênero são frequentemente associados a conceitos de mundo aberto, que permitem que os jogadores se movam e avancem livremente no espaço. O termo "Caixa de Areia" é derivado da natureza inventiva do brinquedo, que permite que as crianças criem quase tudo o que quiserem nele. Baseado em vários elementos interativos dinâmicos, esse tipo de jogo tem muitas variedades. Portanto, o termo é frequentemente usado sem uma definição estrita. Os designers de jogos às vezes definem 
uma Caixa de Areia com o que ela não tem. A Caixa de Areia como gênero de jogo digital, pode ter menos tarefas, batalhas principais, narrativas ou qualquer coisa relacionada ao progresso do jogo.

Amalgamar a areia, faz uma alusão à composição dos sentidos na intuição ou preensão que produz os objetos, ou seja, o objeto-problema está para além do significado (ideias, abstrações, conjuntos, generalizações) ou do referente (designações, substâncias, indivíduos dados), está nos sentidos arranjados de modo complexo em um problema, findando, em sua tensão, por definir um movimento, um estilo, uma relação, algo que possui alguma coerência complexa por estabelecer um arranjo estético (Fonseca et al., 2013). Para que isso aconteça em mundos virtuais, a limitação do jogador em uma Caixa de Areia digital deve ser extremamente pequena, permitindo-lhe vagar e mudar esse mundo. Em contraste com os jogos progressivos, as Caixas de Areia precisam enfatizar a perambulação e permitir que os jogadores selecionem em qual conjunto de gestos preferem se envolver (Oosterhuis et al., 2006). O design de uma Caixa de Areia pode ocorrer em um tipo projeto, no qual os arquitetos podem lentamente adicionar recursos para tornar a experiência do jogo mais nítida e avaliar um elemento por vez.

\section{Design de jogos para a aprendizagem inventiva}

Se projetar jogos convencionais significa desenvolver componentes para progressão com base no motor de jogo, a elaboração da Caixa de Areia corresponde a programação de um motor (mecanismo) para expressar conceitos. Por si só, o conceito de jogo Caixa de Areia é muito ambicioso - "dê para as pessoas uma Caixa de Areia e eles construirão um castelo".

Porém a falta de foco ou de objetivos claros tornam o desenvolvimento desse tipo de jogo um desafio para seus projetistas. Um jogo convencional deve responder apenas às interações corretas enquanto um jogo Caixa de Areia deve responder a todas as interações (Oosterhuis et al., 2006). Mesmo que não exista uma "estrutura de A para B", não significa que o jogador não tenha um objetivo, então, um jogo Caixa de Areia é mais um espaço lúdico sobre "ser" ao invés de "fazer", o que significa que em muitos casos o projetista deve definir o papel do jogador (ou o papel que ele pode desempenhar (Breslin, 2009). Trata-se aqui da relação virtual-atual: não há um polo estável e outro instável, ambos se encontram em tensão, modificando-se na relação que constituem.

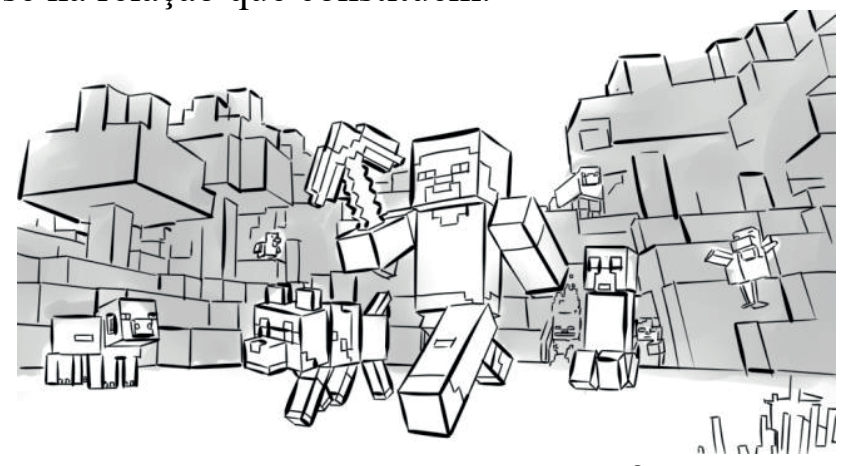

Figura 1 - 0 jogo Minecraft

O jogo Minecraft (figura 1) é grande exemplo de progresso oculto. A estrutura de seu sistema de produção é semelhante a uma escada ramificada (ver figura 3), onde os elementos de produção na parte inferior podem acessar os elementos de produção superiores (ou seja, para ter uma picareta de pedra, o jogador deve primeiro ter uma picareta de madeira para colher os recursos de pedra). No lugar de apresentar um mapa fechado, os projetistas utilizam os conceitos de "atração" e "repulsão". A repulsão se refere ao elementos que repelem o jogador, como armadilhas e perigos. De modo oposto, a atração se refere ao 
elemento que atrai o jogador como ítens e recursos (Breslin, 2009). Esses elementos são distribuídos por todo o espaço e são finitos, então os jogadores devem fazer grandes deslocamentos no cenário, para obter mais recursos para continuar a fabricação. Outro componente de progressão dessa Caixa de Areia é que uma vez que o jogador morre e renasce na origem, o retrocesso torna-se um problema. Quanto mais longe do ponto de origem, mais perigoso ele é, mais equipes é preciso e mais seguro é preciso tornar o ponto de origem para recuar com segurança. Assim como em Minecraft, muitas estruturas de Caixa de Areia podem ser utilizadas (que se combinam).

\begin{tabular}{|l|l|}
\hline parque temático & $\begin{array}{l}\text { o espaço é semeado com recursos para atividades (lutar, fazer compras, } \\
\text { conversar, navegar, etc..). A navegação é feita através de pontos de } \\
\text { referência visíveis. }\end{array}$ \\
\hline exploração de quebra-cabeças & $\begin{array}{l}\text { Os elementos são estruturados por relações espaciais - O alvo está oculto e } \\
\text { deve ser descoberto (por exemplo, itens especiais }\end{array}$ \\
\hline chave e fechadura & $\begin{array}{l}\text { o jogador é impelido por porta trancada a encontrar uma chave } \\
\text { algumas portas são bloqueadas por um quebra-cabeça }\end{array}$ \\
\hline migalhas de pão & $\begin{array}{l}\text { distribuição de itens colecionáveis pelo cenário } \\
\text { organização de um caminho por meio de migalhas de pão colecionáveis } \\
\text { Itens ocultos encontráveis ao acaso }\end{array}$ \\
\hline navegação em camadas & $\begin{array}{l}\text { item modificam os recursos de navegação. Navegação anteriormente } \\
\text { complexa torna-se mais simples }\end{array}$ \\
\hline rede de busca & $\begin{array}{l}\text { as missões levam uma a outra ou a um novo centro de missões, com loops } \\
\text { aninhados complexos. }\end{array}$ \\
\hline ataques de base & $\begin{array}{l}\text { o jogador está livre para se mover em um mundo com várias bases } \\
\text { jogador se infiltrar para atingir o núcleo ou conquistar. }\end{array}$ \\
\hline
\end{tabular}

\section{Adaptado de neoshaman, (2016)}

Existem vários exemplos de jogos com essas estruturas. Podemos citar como jogos estilo parque temático, os jogos da empresa Rock Star Games, tais como GTA (Grand Thief Auto) e Red Dead Redemption bem como o aclamado Cyberpunk 2077. A série de jogos Zelda, da Nintendo é composta por diversos elementos tais como a mecânica de chave e fechadura e exploração de quebra cabeças. O jogo Metal Gear V, Phantom Pain é um exemplo de um jogo baseado em ataques de base. A série Assassins Creed da francesa Ubisoft, por sua vez mantém o interesse do jogador através da distribuição de itens colecionáveis pelo cenário. Os jogos de mundo aberto precisam de elementos temáticos e uma identidade coerente. Um jogo como esse, precisa oferecer para as pessoas um motivo real para jogá-lo oferecendo mundos e espaços habitáveis para possíveis ações.

\section{A elaboração de jogos para a aprendizagem inventiva.}

O microfluxo pode ser definido como um estado de espírito intenso e focado onde o jogador sente prazer e satisfação, muitas vezes gerado por uma série de conquistas de sucesso.

Nos jogos convencionais o microfluxo é a força motriz do macrofluxo. Em jogos Caixa de Areia o microfluxo aglutina e constitui as constelações que vão mesclar o espaço de problematização e consequentemente o território existencial. 


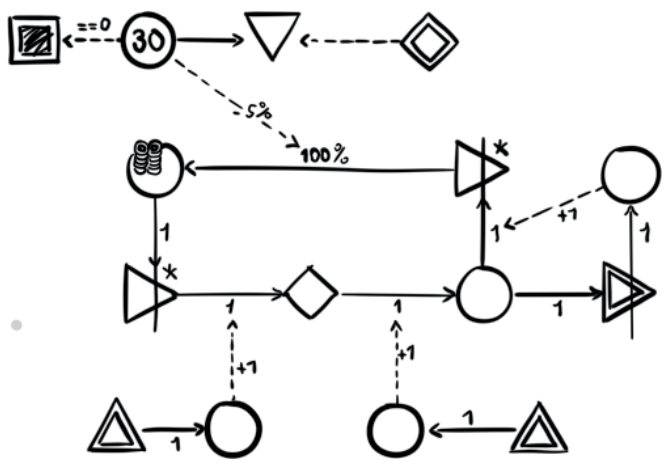

Figura 2 - Diagrama Machinations de um microfluxo de construção

O microfluxo configura uma série de pequenas realizações. Ele se sustenta por um curto período, mas é emocionalmente intenso. Isso é repetido em um ciclo do jogo para manter os usuários jogando. É uma resposta positiva para manter a jogabilidade emergente. Feedbacks positivos e sistemas de recompensa são maneiras recorrentes de implementar o micro fluxo, que leva o jogador a mergulhar na atividade. O ritmo do jogo também pode ajudar a impulsionar a jornada do jogador e, eventualmente, pode a experiência tornar mais envolvente (Void, 2020). A figura 2, representa o diagrama para uma mecânica básica de um jogo de construção, utilizando a ferramenta Machinations(Adams et al., 2012). Os triângulos representam as ações do jogador, que colocam em marcha o micro fluxo, que a cada interação, oferece um nível de desafio crescente.

O microfluxo é perpetuado por sucessos repetidos em rápida sucessão, o que fornece feedback emocional positivo e tangível, encorajando o jogador a continuar no micro fluxo; isso é conhecido como ciclo virtuoso. Por meio do reforço positivo, eles se tornam mais intrinsecamente motivados para jogar e, ao jogar bem, são recompensados com um reforço mais positivo. O microfluxo é curto intencionalmente, para que o jogador possa experimentá-lo com mais frequência e reconhecê-lo facilmente como uma experiência altamente recompensadora. Ao fazer isso, o designer pode usar sinais e feedback semelhantes entre os diversos desafios do jogo e ajudar a promover o microfluxo com mais frequência e facilidade. Ao se projetar um jogo para a aprendizagem inventiva, implementar a capacidade de criar configurações ou construções funcionais, estetica e sensorialmente agradáveis que o jogador possa vivenciar o sentido de autoria é fundamental para que a base de jogadores alcance o estado de fluxo em seu jogo. Minecraft é uma forma muito destilada dessa inventividade, não oferecendo objetivos reais além da sobrevivência diária e a rede de conquistas no jogo,

Mas mesmo em um jogo como o Minecraft, em que o jogador tem liberdade para explorar e construir o que quiser, ele tem objetivos que emergem do sistema de jogo que impulsionam sua experiência no universo ficcional, como construir uma megaestrutura ou estocar recursos para uso posterior. 


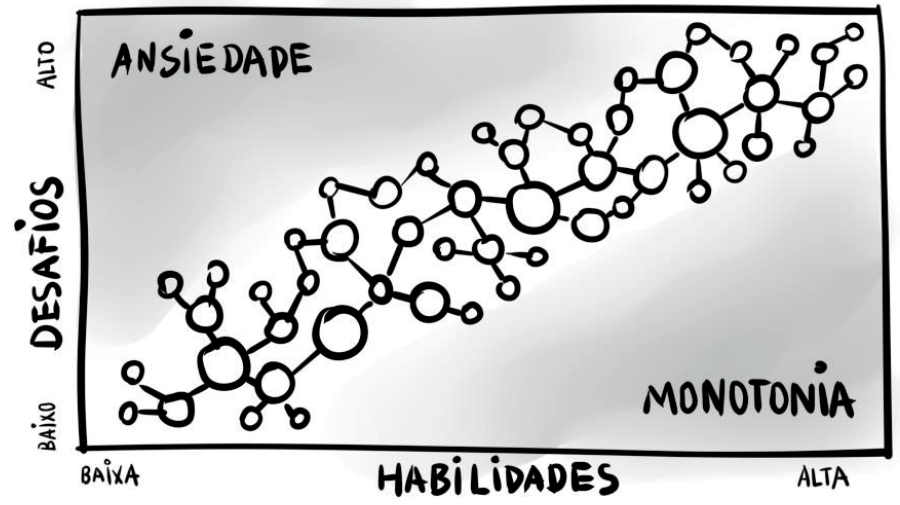

Figura 3 - Macro fluxo de progressão em jogos estilo Caixa de Areia.

Embora o fluxo seja um objetivo bastante difícil em jogos Caixa de Areia onde uma das características do espaço de problematização seja a ausência de foco, e que o excesso de objetivismo pode atentar contra um projeto de aprendizagem inventiva e induzir a uma subjetividade institucionalizante, o desafio do desenvolvimento de um jogo de tal natureza é um desafio de equilíbrio. É do balanceamento da Paidia com o Ludus, movidos pelo feedback constante, que se dará ritmo para a experiência inventiva. O jogador em um mundo de possibilidades criando e sendo criado. Assim, o arquiteto desse espaço precisa conceber uma ferramenta para a geração de artefatos ao mesmo tempo que oferece uma experiência estruturada, garantindo que a problematização seja continuada e não interrompida pela falta de foco, que de maneira dosada, irão permitir ao jogador uma maior chance de passar por estados de autoconsciência. $\mathrm{O}$ jogador toma contato com a diferença com uma vertigem dosada pela repetição. (Sayre, 2017).

No projeto de jogos Caixa de Areia e nos jogos de característica emergente no geral, é importante dosar a inclusão de elementos novos devido ao escalamento de complexidade e perigo de criação de um espaço estéril. Para que isso não ocorra, é importante introduzir processos de projeto de jogos como o design racional e design atômico. O design racional trata da eliminação de informações desnecessárias, tornando os componentes dinâmicos inerentemente legíveis, compreensíveis e aparentes, introduzindo a mecânica de maneira ordenada e facilmente compreensível, preservando as curvas de aprendizagem e dificuldade de um jogo, no já mencionado macrofluxo. O design atômico é a abstração que divide os componentes de jogo em uma gramática conjugável e permite a conceitualização necessária para o design racional(McMillan, 2013).

$\mathrm{O}$ design atômico, como as partículas inimaginavelmente pequenas que o denominaram, representa um nível muito básico no design do jogo em que o designer examina os pequenos fatores influentes e encontra maneiras claras de aproveitar as suas propriedades na busca por criar um ambiente divertido, equilibrado e compreensível e experencialmente enriquecedor (McEntee, 2012).

Um dos princípios básicos do design atômico é considerar o tempo todo as habilidades e entradas necessárias para uma determinada situação no jogo. Ao quebrar o número e a dificuldade das entradas e a complexidade das habilidades envolvidas, é mais fácil racionalizar a maneira de desafiar o jogador e evitar que o desafio caia na ordem da qual ele não pode escapar devido ao nível de complexidade exigido. Uma mecânica de jogo é um desafio baseado em uma entrada e habilidade específicas que podem ser alteradas por parâmetros atômicos para aumentar a dificuldade inerente do desafio. Para definir com sucesso uma mecânica, devemos primeiro definir uma habilidade para associar a ele, de forma que saibamos o que será desafiado.

Esses dois conceitos ganham importância especial na elaboração de jogos Caixa de Areia, 
pois a metáfora desse espaço com uma matéria que pode ser transmutada em qualquer coisa, mas não é coisa nenhuma, é facilmente passível de cair em um dos perigos da Paidia extrema: o caos absoluto. Essas concepções vêm ajudar a estruturar os campos de problematização que tornarão a dicotomia entre Paidia e Ludus a motriz para que a experiência seja fluída e assim gerar um sistema propositivo na espessura temporal da experiência, operando com para a cognição inventiva.

Isso significa fornecer aos jogadores mecanismos interessantes e detalhados e aproveitá-los ao máximo por meio de um design de nível inteligente e simplificado, em vez de injetar o jogo inteiro com uma mecânica de jogo única em falsa profundidade. Um bom motor pode carregar o jogo inteiro adicionando elementos de jogo apropriados para ajudar a enfatizar a praticidade e profundidade do mecanismo.

Adotar processos na elaboração de espaços de invenção não designa a limitação de uma forma, mas a convergência na direção de um fundamento; não mais a distinção de formas, mas a correlação do fundado e do fundamento; não mais a

suspensão da potência, mas o elemento em que a potência é efetuada e fundada(Gilles Deleuze, 2018).

\section{Conclusões}

O roteiro aqui proposto procurou oferecer uma nova dimensão na compreensão de como se dá o processo de desenvolvimento de jogos para a aprendizagem inventiva ao estabelecer relações entre a aprendizagem inventiva, jogos Caixa de Areia e processos de game design voltados para esse fim. Desse debate derivamos algumas questões, que nos levam à proposta para formulação de algumas linhas a serem seguidas, no projeto de jogos para aprendizagem inventiva. Problematizar é navegar em um universo de sinais, portanto é desejável num projeto de jogo Caixa de Areia, oferecer possibilidades explícitas e marcar claramente quais caminhos oferecem mecanismos significativos.

O jogo Caixa de Areia encoraja a participação, permitindo que as pessoas explorem o espaço, produzindo resultados desconhecidos. Ali as pessoas podem experimentar diferentes papéis e tarefas imaginárias. Porém, planejar uma experiência de jogo emergente é uma tarefa dependente de um encontro entre processos. De um lado o design da Caixa de Areia é a criação de uma ferramenta para estimular a imaginação, mas de outro, é preciso considerar quais são os elementos que serão disponibilizados pois enquanto o excesso de controle vai inibir a desejada inventividade da experiência, a falta de um processo em sua concepção pode significar pode resultar num jogo infértil.

Este é um dos benefícios de tornar o design racional como parte da pré-produção de jogos inventivos. As iterações tornam-se mais rápidas e a solução de problemas de design torna-se mais orientada de modo a permitir um melhor mapeamento dos pontos obscuros dos processos unicamente orientados a avaliações arbitrárias.

Usado em uma ampla gama de situações, o termo "Caixa de Areia" corre o risco de ser diluído, confuso e às vezes esquecido. Mais comumente, os jogos Caixa de Areia se integram com elementos criativos em outros gêneros e permitem uma abundante jogabilidade emergente. Isso sugere uma experiência lúdica que potencialmente pode desenhar certos territórios existenciais. Um jogo que exija que jogador a responda ao cenário e sua dinâmica bem como induza a realizar novas perguntas.

Assim, a transição de tempo experimentada durante o jogo para a aprendizagem inventiva permite aos jogadores reconsiderar o tempo como uma duração, ao invés de uma herança universal de unidades objetivas e mensuráveis observadas como um sujeito unificado. Nesse estado, o jogador é mais sensível aos sinais enviados por diferentes componentes, permitindo que se abra aos devaneios de outros componentes, expandindo assim o seu território existencial. 


\section{Referências}

Adams, E., \& Dormans, J. (2012). Game mechanics: advanced game design. New Riders.

Bergson, H. (1999). Matéria e memória: ensaio sobre a relação do corpo com o espírito. In São Paulo. Cayetano Colomino. Retrieved from http://charlezine.com.br/wpcontent/uploads/Matéria-e-Memória-Bergson.pdf

Breslin, S. (2009). Gamasutra - The History and Theory of Sandbox Gameplay. Retrieved from

https://www.gamasutra.com/view/feature/132470/the_history_and_theory_of_sandbox ..php

Deleuze, G. (1988). Bergsonism. Zone Books. Retrieved from https://books.google.com.br/books?id=W7-OQgAACAAJ

Deleuze, Gilles. (2018). Diferença e repetição. Editora Paz e Terra.

Fonseca, T. M. G., \& Costa, L. A. (2013). As durações do devir: como construir objetosproblema com a cartografia. Fractal : Revista de Psicologia, 25(2), 415-431. doi: 10.1590/S1984-02922013000200012

Kastrup, V. (2001). Aprendizagem, arte e invenção. Psicologia Em Estudo, 6(1), 17-27. doi: $10.1590 / \mathrm{S} 1413-73722001000100003$

McEntee, C. (2012). Gamasutra - Rational Design: The Core of Rayman Origins. Retrieved from https://www.gamasutra.com/view/feature/167214/rational_design_the_core_of_php

McMillan, L. (2013). Gamasutra: Luke McMillan's Blog - The Rational Design Handbook: An Intro to RLD. Retrieved from https://www.gamasutra.com/blogs/LukeMcMillan/20130806/197147/The_Rational_De sign_Handbook_An_Intro_to_RLD.php

neoshaman. (2016). What makes a great sandbox game? - Unity Forum. Retrieved from https://forum.unity.com/threads/what-makes-a-great-sandbox-game.413189/

Oosterhuis, K., Feireiss, L., \& Bouwkunde, T. U. D. F. (2006). The Architecture Colaboratory: GameSetandMatch II : on Computer Games, Advanced Geometries, and Digital Technologies. Episode Publishers. Retrieved from https://books.google.com.br/books?id=tXBdOoZ-faYC

Pascual, J. G., \& Justa, R. (2009). A aprendizagem inventiva no ensino de Psicologia. Arquivos Brasileiros de Psicologia, 61, 23-34. Retrieved from http://pepsic.bvsalud.org/scielo.php?script $=$ sci_arttext\&pid=S1809$52672009000300004 \& \mathrm{nrm}=$ iso

Sayre, J. (2017). Flow State and Interactive Media. Meet Mihály Csíkszentmihályi | by Jonathan Sayre | Interactive Designer's Cookbook | Medium. Retrieved from https://medium.com/interactive-designers-cookbook/flow-state-and-how-your-gamecan-benefit-by-triggering-it-9c1909958fd1

Void. (2020). Retrieved from https://www.void1gaming.com/post/flow-theory-in-gamedesign 